Filigrane

Écoutes psychothérapiques

\title{
Par-delà le masculin et le féminin
}

\section{André Lussier}

Volume 20, numéro 2, automne 2011

URI : https://id.erudit.org/iderudit/1007613ar

DOI : https://doi.org/10.7202/1007613ar

Aller au sommaire du numéro

\section{Éditeur(s)}

Revue Santé mentale au Québec

\section{ISSN}

1192-1412 (imprimé)

1911-4656 (numérique)

Découvrir la revue

Citer ce compte rendu

Lussier, A. (2011). Compte rendu de [Par-delà le masculin et le féminin]. Filigrane, 20(2), 101-103. https://doi.org/10.7202/1007613ar d'utilisation que vous pouvez consulter en ligne.

https://apropos.erudit.org/fr/usagers/politique-dutilisation/ 


\section{Par-delà le masculin et le féminin}

\section{André Lussier}

J e viens de terminer la lecture d'un livre qui à mon sens n'a pas encore reçu toute l'attention qu'il mérite, Par-delà le masculin et le féminin, de Claude Lévesque (Paris: Aubier, 2002).

L'auteur, professeur retraité de Philosophie à l'Université de Montréal, est l'un de ces philosophes comme on souhaiterait qu'il y en ait davantage. Il fait preuve d'une connaissance remarquable de la pensée de Freud.

C'est la première section du livre, la plus substantielle, qui retiendra mon attention. En substance, elle porte sur les positions pour le moins étonnantes, sinon renversantes, de Freud sur le masculin et le féminin. Son respect de Freud n'empêche pas Claude Lévesque de le critiquer avec sagesse et profondeur, comme c'est le cas dans son livre. Son avant-propos nous donne une idée de l'étendue de son regard sur le sujet annoncé; je le cite : «La question du masculin et du féminin exige un traitement si radical qu'il faut convoquer toutes les ressources de la philosophie, d'une philosophie capable de se porter au-delà de la philosophie, pour le soutenir et le pousser toujours plus loin». Avec discernement et démonstrations à l'appui, Claude Lévesque analyse les grandes faiblesses de la pensée de Freud dans ses tentatives pour distinguer l'un de l'autre le masculin et le féminin. Nous savons que ce n'est pas sur ce terrain que Freud a fait la preuve de son génie. Au contraire, Claude Lévesque expose avec clarté à quel point, sur ce sujet majeur, Freud, je dirais, a négligé d'être freudien; plutôt que de poursuivre son génial penchant qui lui permettait d'aller au-delà du conscient et du rationnel, de façon à nous donner accès, pour la première fois dans l'histoire, aux mystères des névroses et du rêve, il s'est contenté cette fois de faire front commun avec ses prédécesseurs, à commencer par Aristote. Au lieu de psychanalyser le verbatim des petits garçons, des petites filles et de ses patients, il s'est enligné sur l'inébranlable tradition philosophique et psychologique sur le sujet. Claude Lévesque analyse certains des principaux 
motifs qui aident à comprendre cette si étonnante lacune anti-freudienne dans l'œuvre de Freud.

Sur son parcours, Lévesque scrute les ambiguïtés et les contradictions inévitables dans les affirmations de Freud. Ainsi, de poursuivre Lévesque: «Après avoir indiqué... qu'on doit se garder d'associer trop rapidement l'opposition masculin/féminin à l'opposition activité/passivité, Freud ne laisset-il pas entendre que la libido est masculine pour la seule raison que, en tant que pulsion, elle est toujours active» (p. 29). Comme dit Lévesque, «Freud a recours à une notion dont il vient de dénoncer l'ambiguiité». L'essai de l'auteur va plus loin, il posera la question de base, je le cite: «D'où vient que la sexualité - qui, initialement et à priori, est sans loi ou qui ne saurait donc avoir d'autre loi que la démesure et la multiplicité - se donne, par une étrange nécessité, fondée apparemment sur la maturation biologique ou le destin anatomique, un modèle unique (le Phallus) et une loi unique (la loi séparatrice et impérative du Père) et oblige, du coup, à définir le féminin de manière purement négative ou privative, c'est-à-dire comme un sexe en moins, par rapport au sexe emblématique? Comment non seulement le deux de la bisexualité mais aussi le multiple se trouvent-ils réduits à l'UN ?» (p. 35).

C'est donc quand il veut cerner ce qui distingue le masculin du féminin, que Freud se laisse prendre dans les filets des «impératifs culturels et les préjugés du discours dominant», qu'il est pris au piège des "préjugés qui font plier la perception ». Et ainsi, l'Ego mâle se gonfle d'amour-propre, participant à la parade séculaire du glorieux phallocentrisme.

Pour le plus grand intérêt du lecteur, Claude Lévesque réfléchit sur la pensée de deux femmes psychanalystes qui se sont prononcé de façon marquante sur cette question, Sarah Kofman (L'énigme de la femme, 1980) et Monique Schneider (Généalogie du masculin, 2000). Dans la deuxième partie du volume, il se penche aussi sur la pensée de trois philosophes contemporains pour échanger avec eux sur le même sujet. La pensée de Lacan fait également l'objet de sa critique.

Un dernier mot pour finir sur une question. Si j'ai bien compris Claude Lévesque, il semble concevoir l'être humain, à la naissance, comme une tabula rasa, susceptible, à priori, d'être absolument dépendante des conditions du milieu, donc emprise incontournable de la culture sur la nature. Si c'est bien là sa position comme je le crois, je ne partage pas cet absolu, bien qu'il ne me soit pas difficile d'en saisir le rationnel. En principe, je reste obstinément fidèle à la primauté des forces de la nature, primauté relative à la toute première origine des choses (pléonasme voulu) à la naissance, peu importe avec 
quelle intensité. Dès la naissance, biologiquement et fort probablement psychologiquement aussi, la nature prédispose la fille vers la féminité et le garçon vers la masculinité. Ceci dit, je suis le premier à savoir que dès la naissance aussi, la culture (le milieu) est en mesure d'invertir cet ordre des choses, et faire en sorte que la fille puisse en venir à se tracer une identité masculine et le garçon, une identité féminine. C'est là un point secondaire de discussion qui n'affecte en rien la valeur de fond du remarquable essai de Claude Lévesque. Travail majeur dont il faudra à l'avenir tenir compte. Je le recommande vivement.

André Lussier

200, Des Sommets, app. 1001 Île des Sœurs (Québec) H3E 2B4 